\title{
Pessary versus cerclage versus expectant management for cervical dilation with visible membranes in the second trimester.
}

\author{
Alexis C. Gimovsky \\ Thomas Jefferson University \\ Anju Suhag \\ Thomas Jefferson University \\ Amanda Roman \\ Thomas Jefferson University \\ Burton L. Rochelson \\ Hofstra North Shore-LIJ School of Medicine \\ Follow this and additional works at: https://jdc.jefferson.edu/obgynfp \\ incenzo Berghella

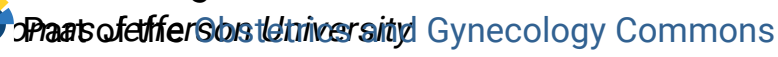 \\ Let us know how access to this document benefits you
}

\section{Recommended Citation}

Gimovsky, Alexis C.; Suhag, Anju; Roman, Amanda; Rochelson, Burton L.; and Berghella, Vincenzo, "Pessary versus cerclage versus expectant management for cervical dilation with visible membranes in the second trimester." (2016). Department of Obstetrics and Gynecology Faculty Papers. Paper 36.

https://jdc.jefferson.edu/obgynfp/36

This Article is brought to you for free and open access by the Jefferson Digital Commons. The Jefferson Digital Commons is a service of Thomas Jefferson University's Center for Teaching and Learning (CTL). The Commons is a showcase for Jefferson books and journals, peer-reviewed scholarly publications, unique historical collections from the University archives, and teaching tools. The Jefferson Digital Commons allows researchers and interested readers anywhere in the world to learn about and keep up to date with Jefferson scholarship. This article has been accepted for inclusion in Department of Obstetrics and Gynecology Faculty Papers by an authorized administrator of the Jefferson Digital Commons. For more information, please contact:

JeffersonDigitalCommons@jefferson.edu. 
Title: Pessary vs. Cerclage vs. Expectant Management for Cervical Dilation with Visible Membranes in the Second Trimester

Alexis C. Gimovsky MDa, Anju Suhag MDa, Amanda Roman, $\mathrm{MD}^{\mathrm{a}}$, Burton Rochelson, $M D^{b}$, Vincenzo Berghella, $M^{a}$

a. Division of Maternal Fetal Medicine

Department of Obstetrics and Gynecology

Sidney Kimmel College of Medicine at Thomas Jefferson University

Philadelphia, PA

b. Division of Maternal Fetal Medicine

Department of Obstetrics and Gynecology

Hofstra North Shore-LIJ School of Medicine

Manhasset, NY

Corresponding Author:

Alexis C. Gimovsky, MD 


\section{Chestnut St}

$1^{\text {st }}$ Floor

Philadelphia, PA 19107

P-215-955-9200

F- 215-955-5041

Email: alexis.gimovsky@jefferson.edu

Reprints will not be available.

Word count (abstract): 199

Word count (full text): 1454

Short version of title: Pessary vs cerclage for exposed membranes in the second trimester

Key words: cerclage, pessary, advanced cervical dilation, exposed membranes 
Abstract Objective: We evaluated pessary for dilated cervix and exposed membranes for prolonging pregnancy compared to cerclage or expectant management.

Methods: Multicenter retrospective cohort study of women, 15-24 weeks, singleton pregnancies, dilated cervix $\geq 2 \mathrm{~cm}$ and exposed membranes. Women received pessary, cerclage or expectant management. Primary outcome was gestational age at delivery. Secondary outcomes were time until delivery, preterm premature rupture of membranes (PPROM) and neonatal survival.

Results: 112 women met study criteria; 9- pessary, 85- cerclage and 18- expectant management. Mean gestational age at delivery was $22.9 \pm 4.5$ weeks with pessary, $29.2 \pm 7.5$ weeks with cerclage and $25.6 \pm 6.7$ weeks with expectant management $(p=$ $0.015)$. Time until delivery was $16.1 \pm 18.9$ days in the pessary group, $61.7 \pm 48.2$ days in the cerclage group and $26.8 \pm 33.4$ days in the expectant group $(p<0.001)$. PPROM occurred less frequently and neonatal survival increased in women with cerclage. There was a significant difference in all perinatal outcomes with cerclage compared with either pessary or expectant management.

Conclusions: Perinatal outcomes with pessary were not superior to expectant management in women with dilated cervix with exposed membranes in the second trimester in this small retrospective cohort. 
Declaration of Interest: The authors report no declarations of interest. This study was not funded. 


\section{Introduction}

Preterm birth (PTB) occurs in $11.38 \%$ of pregnancies in the United States and is the principal cause of perinatal morbidity and mortality [1].

Women with singleton pregnancy, dilated cervix and exposed membranes during the second trimester have a $90 \%$ rate of preterm birth (PTB) [2-6]. These women represent a treatment challenge. Current management options are limited and include expectant management, physical exam indicated cerclage (PEIC) or pessary placement if there is no contraindication for continuing pregnancy.

There is no known proven benefit in prolongation of pregnancy with bed rest, and it is known to increase the risks of DVT and PE; maternal deconditioning also increases the risk of preterm birth [7].

PEIC performed usually between 14 to 24 weeks has instead been associated with decreased PTB $<28$ and $<32$ weeks by $70 \%$ and $64 \%$ respectively, decreased neonatal morbidity and improved neonatal survival, when compared with expectant management. 3-6, 8 The risk of PEIC placement includes: rupture of membranes (4\% $-19 \%)$, bleeding from cervical laceration and intrauterine infection [8-13]. 
Pessaries have been used to prevent preterm birth for over 50 years and have been evaluated for treatment of short cervix [14-17]. Mechanically, the pessary is thought to change the angle between the cervical canal and the uterus to help displace the uterine weight and block the internal os. There are no data yet regarding the efficacy of pessary in women with second trimester cervical dilatation on physical exam. Our objective was to evaluate whether insertion of a pessary in women with dilated cervix $\geq$ 2 centimeters provides better outcomes compared to PEIC or expectant management. 


\section{Materials and Methods}

This is a retrospective cohort of all pregnancies identified with dilated cervix $\geq 2$ centimeters and visible membranes in the second trimester of pregnancy managed between September 1994 and June 2014 at North Shore University Hospital, Long Island Jewish Medical Center and Thomas Jefferson University Hospital. The Institutional Review Board of both participating centers approved the study protocol. Patients were identified by ultrasound records, hospital records and delivery records. Both centers have extensive experience with the management of advanced cervical dilation early in pregnancy and have a level three neonatal intensive care unit (NICU) associated with their antepartum unit. In all cases, exposed membranes were diagnosed on speculum exam. This study was exempt from the Institutional Review Board.

Inclusion criteria were asymptomatic women between 15-24 weeks, with singleton pregnancies and a dilated cervix $\geq 2 \mathrm{~cm}$ and $\leq 4 \mathrm{~cm}$ with exposed membranes. Exclusion criteria were fetal anatomical or genetic anomaly, bleeding, clinical chorioamnionitis, medically indicated preterm delivery or evidence of progressive preterm labor or miscarriage. Cervical length screening and progesterone(vaginal or intramuscular) were not routinely used during the entire study time period and thus were not incorporated in the inclusion or exclusion criteria. Demographic information was recorded for each patient. Matching neonatal records were reviewed. Women received either pessary, PEIC or expectant management as determined by their primary 
obstetric provider. The Bioteque cup \# 3 pessary was used in the pessary group. Pessaries were only used at one center, Thomas Jefferson University Hospital. Physical exam indicated cerclage was done with a \# 5 mersiline suture or a $5 \mathrm{~mm}$ mersiline tape in a McDonald technique. Expectant management was on either inpatient or outpatient depending on provider. Maternal activity, antibiotics, tocolysis and progesterone were given at the discretion of the primary obstetrician.

Primary outcome was gestational age (GA) at delivery. Secondary outcomes were interval between intervention and delivery, rate of preterm premature rupture of membranes (PPROM) and neonatal survival at discharge. Data analysis was conducted using GraphPad for Windows 8.0. The three groups were compared using the Analysis of Variance (ANOVA) test or the Student t-test for continuous variables and Fischer Exact test for categorical data. A Kaplan-Meier curve was used to evaluate gestational age at delivery. 


\section{Results}

Overall, 112 pregnancies were identified for retrospective analysis. The pessary group included 9 women. Eighteen women were expectantly managed and 85 women underwent physical exam indicated cerclage. 46 women were from North Shore University Hospital, Long Island Jewish Medical Center and 66 women were from Thomas Jefferson University Hospital. Maternal demographics were not significantly different between the three hospitals or among treatment groups (Table I).

The mean gestational age at delivery was $22.9 \pm 4.5$ weeks with pessary, $29.2 \pm 7.5$ weeks with cerclage and $25.6 \pm 6.7$ weeks with expectant management, $p=0.015$ (Table II). Perinatal outcomes were not significantly different between pessary and expectant management (Table II).

The risk of preterm birth between the three groups was assessed by Kaplan-Meier survival analysis (Figure 1). There was a significant difference in gestational age at delivery with cerclage compared with either pessary or expectant management (Figure 1).

PEIC significantly improved perinatal outcomes of PPROM $(p<0.001)$ and neonatal survival on discharge $(P=0.03)$ when compared with expectant management or 
pessary. Additionally, the latency period between diagnosis of exposed membranes and delivery was significantly prolonged in the PEIC group $(p=<0.001)$ (Table II). 


\section{Comment}

The management of women with a dilated cervix and visible membranes in the early second trimester is a clinical challenge. We sought to evaluate pessary as an alternative method to PEIC. Perinatal outcome of women treated with pessary was not significantly different than expectant management. PEIC remains the best therapeutic choice for these women.

It is suspected that a dilated cervix and visible membranes in the early second trimester is the terminal phase of the spectrum of cervical insufficiency, with a short cervix being a leading clinical sign of this process. We wanted to evaluate whether a cervical pessary, which has shown promise in women with a short cervix, could be beneficial to women with the more concerning diagnosis of advanced cervical dilation[15-17].

For women with advanced cervical dilation, evidence of treatment options is limited and mostly retrospective, as in our study. The only randomized control trial of PEIC was performed by Althuisius et $\mathrm{al}^{6}$. Women with membranes at or beyond the cervical os before 27 weeks of gestation were treated with PEIC and antibiotics or bed rest. Both the PEIC group and controls were placed on strict bed rest until 30 weeks gestational age. Twenty three women (16 singleton and 7 twins) were randomized to cerclage with indomethacin, or bed rest only. PTB $<34$ weeks and composite neonatal morbidity, were significantly lower in the cerclage and indomethacin group as compared to the control group. Several retrospective observational series, mostly with no controls, also have 
claimed benefit of PEIC [5]. The largest cohort study was published in 2007 by Pereira et al [8]. They evaluated women with a dilated cervix who underwent expectant management vs $\mathrm{PEIC}$. They reported a $92 \%$ reduction in $\mathrm{PTB}<28$ weeks, a greater than 10-fold increase in neonatal survival, higher birth weight and a prolongation of pregnancy by 10 weeks with PEIC, compared with no cerclage, in singletons with $\geq 1$ $\mathrm{cm}$ of cervical dilatation by digital examination between $140 / 7-256 / 7$ weeks. There is some evidence that PEIC may be beneficial in reducing PTB, but larger well designed randomized trials are needed to confirm the benefit of this intervention. Despite this evidence, there are many providers who do not perform PEIC as they feel the risk may exceed the benefit [18].

In this small retrospective cohort, we again confirmed the benefit of PEIC in women with dilated cervix and visible membranes in the early second trimester. Vaginal pessary, however, did not prove to be better at prolonging the pregnancy interval compared to expectant management. Some of the weaknesses of this study was that it was a small study over a long time period and that the data was retrospective. Provider and selection bias may have played a role as to why certain patients received different treatments. For example, the assessment of uterine activity prior to intervention was up to the provider, and the diagnosis of chrorioamnionits was not uniformly made on amniocentesis, as this was a retrospective study. Women who were contracting or who had hard evidence of amniocentesis are more likely to have been placed in the expectant group. Additionally, data on tocolytics, antibiotics and progesterone were not available for all patients. Although the cervical dilation and demographics and risk 
factors were similar amongst the groups, there may have been other factors involved in the pessary group that made them higher risk for delivery. Lastly, it is important to note that the time criterion of this study was prolonged, and the clnical decision making has changed over this period.

Physical exam indicated cerclage remains the best treatment in prolonging pregnancy in women with singleton pregnancies with exposed membranes in the second trimester. In regards to perinatal outcomes, pessary was not superior to expectant management in this small retrospective analysis. 


\section{References}

1. Hamilton BE, Martin JA, Osterman M, Curtin SC. Births: Preliminary data for 2013. National Vital Statistics Reports. 2014; 63(2).

2.Debby A, Sadan O, Glezerman M, Golan A. Favorable outcome following emergency second trimester cerclage. Int J Gynaecol Obstet. 2007; 96(1):16-9.

3. Novy MJ, Gupta A, Wothe DD, Gupta S, Kennedy KA, Gravett MG. Cervical cerclage in the second trimester of pregnancy: a historical cohort study. Am J Obstet Gynecol. 2001;184(7):1447-56.

4. Olatunbosun OA, al-Nuaim L, Turnell RW. Emergency cerclage compared with bed rest for advanced cervical dilatation in pregnancy. International surgery. 1995;80(2): $170-4$.

5.Daskalakis G, Papantoniou N, Mesogitis S, Antsaklis A. Management of cervical insufficiency and bulging fetal membranes. Obstet Gynecol. 2006;107(1):221-6.

6. Althuisius SM, Dekker GA, Hummel P, van Geijn HP, Cervical incompetence prevention randomized cerclage trial: emergency cerclage with bed rest versus bed rest alone. Am J Obstet Gynecol. 2003;189(4):907-10.

7. Sciscione AC, Maternal activity restriction and prevention of preterm birth. Am J Obstet Gynecol. 2010;202(3):232 e1-5. doi: 10.1016/j.ajog.2009.07.005.

8.Pereira L, Cotter A, Gomez R, et al. Expectant management compared with physical examination-indicated cerclage (EM-PEC) in selected women with a dilated cervix at 
14(0/7)-25(6/7) weeks: results from the EM-PEC international cohort study. Am J Obstet Gynecol. 2007;197(5):483 e1-8.

9.Airoldi J, Pereira L, Cotter A, et al. Amniocentesis prior to physical exam-indicated cerclage in women with midtrimester cervical dilation: results from the expectant management compared to Physical Exam-indicated Cerclage international cohort study. Am J Perinatol 2009;26(1):63-8.

10. Ventolini G, Genrich TJ, Roth J, Neiger R. Pregnancy outcome after placement of 'rescue' Shirodkar cerclage. J Perinatol 2009;29(4): 76-9.

11. Higuchi M, Hirano H, Maki M. Emergency cervical cerclage using a metreurynter in patients with bulging membranes. Acta obstetricia et gynecologica Scandinavica 1992; 71(1):34-8.

12.Wong GP, Farquharson DF, Dansereau J. Emergency cervical cerclage: a retrospective review of 51 cases. Am J Perinatol 1993;10(5):341-7

13.Barth WH, Jr., Yeomans ER, Hankins GD. Emergent cerclage. Surgery, gynecology \& obstetrics 1990; 170(4):323-6.

14. Cross, RG, Treatment of habitual abortion due to cervical incompetence. Lancet. 1959(2):127.

15. Goya M. Cervical pessary in pregnant women with a short cervix (PECEP): an open-label randomised controlled trial. Lancet. 2012;379(9828):1800-6.

16. Arabin B. Alfirevic Z. Cervical pessaries for prevention of spontaneous preterm birth: past, present and future. Ultrasound Obstet Gynecol. 2013 Oct;42(4):390-9. 
17. S. Y. Hui, C. M. Chor, T. K. Lau, T. T. Lao, and T. Y. Leung, Cerclage pessary for preventing preterm birth in women with a singleton pregnancy and a short cervix at 20 to 24 weeks: a randomized controlled trial, Am J Obstet Gynecol. 2013;30(4)283-8.

18. Vĕtr M, Hejtmánek P. Rescue cerclage in the treatment of cervical insufficiency. Ceska Gynekol. 2005;70(6):419-25. 